Scotland, UK.

Mucosal mast cells (MMC) are found mainly within the jejunal submucosa. MMC increase in intestinal graft-versus-host reaction, and their degranulation is obseived in parasitic enteropathy. Weaning is assoclated with morphological changes resem bling those seen in mild cell-mediated intestinal injury. We studied MMC in the young rat jejunum in relation 10 weaning changes. Jejunal morphology, crypl cell production rate, intraopithelial lymphocytos (IEL) and goblet colls woro studied, and MMC were counted in rat mast cell protease II antibody (anti-RMCP II) and toluidine blue stained sections. Serum RMCP II was determined with a direct ELISA method. In the next few days following weaning the jejunal villi shortened by about $30 \%$, crypts elongaled by the same amount, crypt cell produc tion rate more than doubled, and the numbers of IEL showed a marked increase. The MMC counts showed a steady increase trom birth to the time of weaning. sharp fall on the Iwo days immediately after weaning. and further increase the reafter. Serum RMCP II level displayed a sudden tise at the time of weaning, with gradual decline thereafler. Mucosal mast cell degranulation, obviously associaled with the event of weaning, may be responsible for the observed mor phological changes through epilhelial cell damage. Weaning is a period of temporary phological changes through epilhelial cell damage. Weaning is a period of lemporary
loss of oral tolerance in rats; this might be a result of jejunal injury caused by mucosal mast cell protease.

\section{SMALL INTESTINE TRANSPLANTATION IN A CHILD}

6 Goulet $O$, Revillon $Y$, Cerf-Bensussan $N$, Nezelof $C, J a n ~ D$ Pellerin D, Ricour C.

Hopital des Enfants Malades Paris France.

After an experimental stage on piglets small intestine transplantation(SIT)using Cyclosporine $A(C s A)$ we now report a human case. $A$ 9 yrs old girl on home parenteral nutrition for short small bowel (volvulus)for 6 yrs was transplanted with $120 \mathrm{~cm}$ small intestine harvested by an isoblood group A 17 yrs old boy pronouced brain dead.Cross match reaction donor and recipient was negative.After aorta and inferior vena cava anastomosis total ischemic time wa $3 \mathrm{~h} 55 \mathrm{mn}$; both graft and own intestine were exteriorized as stomas. Immunosuppression included solumedrol $2 \mathrm{mg} / \mathrm{kg} / \mathrm{d}$ and $\mathrm{CsA}$ as a continuous infusion to maintain serum levels between 200-300 $\mu \mathrm{g} / 1$. Acute graft rejection(GR)occured on day 13 marked only with an increased ileostomy drainage; histologic pattern included progressively=villi oedema, Tcell infiltrates $\left(\mathrm{CD}^{+} / \mathrm{CD}^{+}\right)$, increased HLADR expression by enterocytes, severe crypt damage and ultimately mucosal sloughing.GR was treated with antilymphocyte globulin. No GVH reaction has been was treated with antilymphocyte globulin. No GVH reaction has been
observed.The course after GR was marked with a persistant protein observed.The course after GR was marked with a persistant protein
losing enteropathy up to a progressive intestine recovery as shown by repeated histologic findings, baryum transit(day 30 and 80 ) and start oral feeding from day 60 . Unfortunately from the $6^{\circ}$ month the addition of prolonged CsA IV administration,long term PN and probable viral infection induced severe liver disease and hematologic disorders requiring graft removal after $6 \frac{1}{2}$ months. The patient died.This course demonstrate that 6 months survival is possible after SIT.Small bowel recovery can be achieved despite extensive mucosal destruction bowel recovery can be achieved
caused be acute grart rejection.

\section{7}

COMPARISON OF RETICULIN (ARA) AND ENDOMYSIUM (EMA) ANTIBODIES IN COELIAC DISEASE.

Mäki M, Hällström O, Polanco I, Visakorpi JK.

Departments of Microbiology and Paediatrics, University Central Hospital of Tampere, Finland and Hospital Infantil "La Paz", Madrid, Spain

IgA class ARA and EMA are both suggested to be good indicators of villous atrophy in coeliac disease (CD). We have now done the tests parallelly in children with untreated CD (52), on gluten-free diet $(20)$ and during gluten challenge (10). Children (50) biopsied because of suspected $C D$ and with normal mucosa served as controls. Furthermore 100 adult blood donors mucosa served as controls. Furtherm were tested. Children with untreated CD were both ARA and EMA positive (titres $1: 10$ to $1: 8000$ for both). 5 children with IgA deficiency and flat intestinal mucosa were negative for both tests. During gluten-free diet disappearance of both ARA and EMA correlated well with mucosal recovery. 4 children with normal mucosa were found to have these antibodies in titres $1: 5$ to $1: 200$. They all were brothers and sisters to $C D$ patients. All the others were ARA and EMA negative. One of the blood donors was positive for both tests. On biopsy, subtotal villous atrophy was found. The absorption of antibodies from patient sera with aninal and human tissues and retestine patient sera with aniwal and human tissues and retesting results suggest the antigens for ARA and EMA not to be fully
identical. However, in clinical practise no difference between identical. However, in clinic
ARA and EMA could be seen.
8 IN MICE, GLUTEN IN MATERNAL DIET PRIMES SYSTEMIC IMMUNE RESPONSES TO GLIADIN IN OFFSPRING

\section{R.Troncone, A.Ferguson}

Hospital, Edinburgh, Scotland, UK

Mice reared on a gluten-containing diet (GCD) are immunologically tolerant to gliadin (1). Aim of this study was to investigate whether oral tolerance is recreated in each generation by the ingestion of dietary gluten at weaning, or whether it is transferred from mother to young (as immune status or via passage of antigen) before birth or during lactation.

$B A L B / c$ mice were used, reared on a gluten-free diet (GFD), born to mothers either from a GFD or a GCD colony. After parenteral Immunisation with gliadin, both humoral and cell-mediated immunity were assessed by serum antibody (ELISA) and footpad swelling test, respectively.

Unexpectedly, mice born to mothers from a $C C D$ colony showed systemic immune responses to gliadin significantly higher $(p<0.05)$ than mice born to mothers from a GFD colony. Furthermore, feeding mothers GCD for defined periods before and during pregnancy and during lactation, also resulted in priming of the specific immune responses of the of fspring.

These findings indicate that, in mice, sensitisation to maternal dietary antigens occurs in utero or shortly after birth. This animal model should allow Investigation of the immunological mechanisms concerned.

(1) Troncone R, Ferguson A. Immunological properties of gliadin presented via the gut. 20th Annual Meeting of ESPGAN, Lisbon 1987.

INTESTINAL CELL MEDIATED IMMUNITY (CMI) TO GLIADIN IS INDUCED IN MICE BY PARENTERAL IMMUNISATION AND CONCURRENT GRAFT-VERSUS-HOST (GVH) REACTrON. R.Troncone, A.Ferguson

Gastro-Intestinal Unit, UnIversity of Edinburgh and Western General Hospital, Edinburgh, Scotland, UK

Mucosal CMI to gliadin is likely to be implicated in the pathogenesis of coeliac disease. Our aim was to induce mucosal CMI to gliadin by feeding gluten-containing diet (GCD) to mice previously parenterally immunised with this antigen. $B A L B / c$ mice from a gluten-free diet (GFD) colony were used. They were given parenterally gliadin in complete Freund's adjuvant, and 3 weeks later they were challenged with GCD for 7 days. In further experiments the effect of concurrent GVH reaction was evaluated in BDF1 mice on a CCD, previously immunised with gliadin. CMI responses in small intestinal mucosa were measured by morphometry (villous and crypt length, crypt cell production rate (CCPR), and intraepithellal lymphocytes (IEL) count).

Feeding GCD for a week to mice reared on GFD did not produce any change. Similarly, mice given GCD after having been parenterally inmunised with gliadin did not show mucosal CMI. Mice on GCD given both gliadin immunisation and GVH showed a significant increase $(p<0.05)$ in crypt depth, CCPR and IEL count, in comparison to cortrols given only GVH.

These results indicate that systemic imnunity to gliadin is not sufficient to induce specific intestinal CMI. Additional factors (enhanced antigen presentation, increased intestinal permeability) are also necessary.

AN HLA-DQ ALPHA ALLELE IDENTTFIED AT DNA AND PROTEIN LEVEL IS STRONGLY ASSOCTATED WITH COELIAC DISEASE B.0. Roep, R.E. Bontrop, A.S. Peña* M.C.J.A. van Eggermond, J.J. van Rood and M.J. Giphart.

Depts. of Immunohaematology and Blood Bank and *Gastroenterology, University Hospital, Leiden, The Netherlands.

Susceptibility genes for coelfac disease are assoclated with certa1n HLA-DR genotypes. More recent studies also show strong assoctation with some HLA-DQ alleles. We have examined the presence of disease BSsociated HLA-DQ alleles by restriction fragment length polymorph1sm (RFPL) with the help of a HLA-DQ alpha cDNA probe. This probe showed upon hybridization a highly significant discrepancy between the RFLP of coellac disease significant discrepancy between the RFLP of coellac disease
patients and healthy controls. The $4.0 \mathrm{~kb}$. Bgl II restriction fragment was present in $97 \%$ of coeliac disease patients $(\mathrm{n}=30)$,
compared to $56 \%$ in a healthy control population (n-72) (RR= compared to $56 \%$ in a healthy control population (n-72) (RR=
14.9 ; $p<0.0005$ ). Th1s fragment 18 associated w1th HLA-DR3, -5 , $14.9 ; p<0.0005)$. Th1s fragment 18 associated w1th HLA-DR3, -5 ,
some DRw8, and DRw14Dw16. Th1s was confirmed by the analys is of the panel of 72 homozygous typing cells obtained from the Xth International Workshop on Histocompatibility Testing.

At the product level all coellac disease patients tested sofar have one $D Q$ alpha chain in common, designated HLA-DQ alpha 2.3, which is associated with the $4.0 \mathrm{~kb}$ Bg1 II fragment. Th1s HLA-DQ alpha allele 1dentffied at the DNA level and product level seems to be a better marker for genetic susceptibility to develop coeliac disease than those avallable oofar. 